\title{
Penetrating Abdominal Trauma with Vascular Injury: Case Report
}

\author{
Rodolfo Franco Márquez ${ }^{1 *}$, Marcela Anahí Narro Mártinez², Pedro Chavez \\ Jimenez $z^{2}$, Oscar René Garcia de León ${ }^{2}$ and Estefania Boland Rodriguez ${ }^{3}$
}

${ }^{1}$ Pathology Department, University Hospital, Autonomous University of Nuevo Leon, Mexico

${ }^{2}$ Surgery Department, University Hospital University Hospital, Autonomous University of Nuevo Leon, Mexico

${ }^{3}$ Medical School of the Autonomous University of Nuevo Leon, Mexico

*Corresponding author: Dr. Rodolfo Franco Márquez, Pathology Department, University Hospital, Autonomous University of Nuevo Leon, Mexico

\section{Introduction}

Traumatic injuries account for $9.6 \%$ of the global burden of disease, they represent the third most common cause of death in young adults and adolescents among patients admitted to hospital facilities; penetrating abdominal trauma remains an important cause of mortality and morbidity [1]. This type of lesions can cause vascular injuries that are associated with massive hemorrhage and could develop physiologic exhaustion, resulting in high reported mortality [2]. Inferior's cava injuries secondary to penetrating trauma are rare, accounting for approximately $0.02 \%$ of gunshot wounds to the abdomen [3]. Surgical treatments for this type of lesions represents one of the most difficult challenges with high complications rate, including infections of the graft and vascular dehiscence; a timely and accurate surgical intervention in hands of experienced surgeons is crucial for better results in their management [4].

\section{Case Description}

A 26-year-old male patient was admitted to the emergency room after receiving four gunshots; the first one was in the neck, penetrating through the submental region exiting at the level of the right labial commissure of the mouth. The second gunshot was in the thorax, with an entry wound in the left hemithorax at second intercostal space precisely in middle clavicular line level, with an exit wound in the axillary region. The third was on the right hemithorax with an entry orifice located in the fifth intercostal space posterior axillary line level, with exit orifice located on the fourth intercostal space clavicular middle line level. And the fourth impact was on the abdominal region, passing through the left hypochondrium without exit wound.

At its initial assessment the patient presented tachycardia (135 bpm), hypotension $(90 / 60 \mathrm{mmHg}$ ) and tachypnea (25 bpm); crystalloid solutions were administrated (Hartmann $1000 \mathrm{cc}$ solution); physical examination revealed well ventilated lungs, present heart sounds and pain at soft palpation of the abdomen with muscular resistance, based on the clinical data obtained and without the need of another type of study or instrumental examination it is taken to the operating room in a period no longer than 10 minutes since the admission.

Exploratory laparotomy was executed finding $3000 \mathrm{ml}$ of hemoperitoneum, with grade IV lesions in mesentery and small intestine at 180, 280, 290, $310,330 \mathrm{~cm}$ from Treitz angle of the retroperitoneal hematoma (zone 1); retroperitoneum was accessed finding a lesion on the lateral side of the inferior vena cava of approximately $3 \mathrm{~cm}$ (Figure 1); vascular control of right and left iliac veins was performed as well as vena cava, proper reconstruction was performed with prolene 6-0 continuous suture (Figure 2), followed by intestinal resection with anastomosis at $180 \mathrm{~cm}$ and another intestinal anastomosis at $280 \mathrm{~cm}$; an open drainage is placed located at the surgical bed and a right endopleural catheter was placed obtaining $50 \mathrm{cc}$ serohematic fluid. 


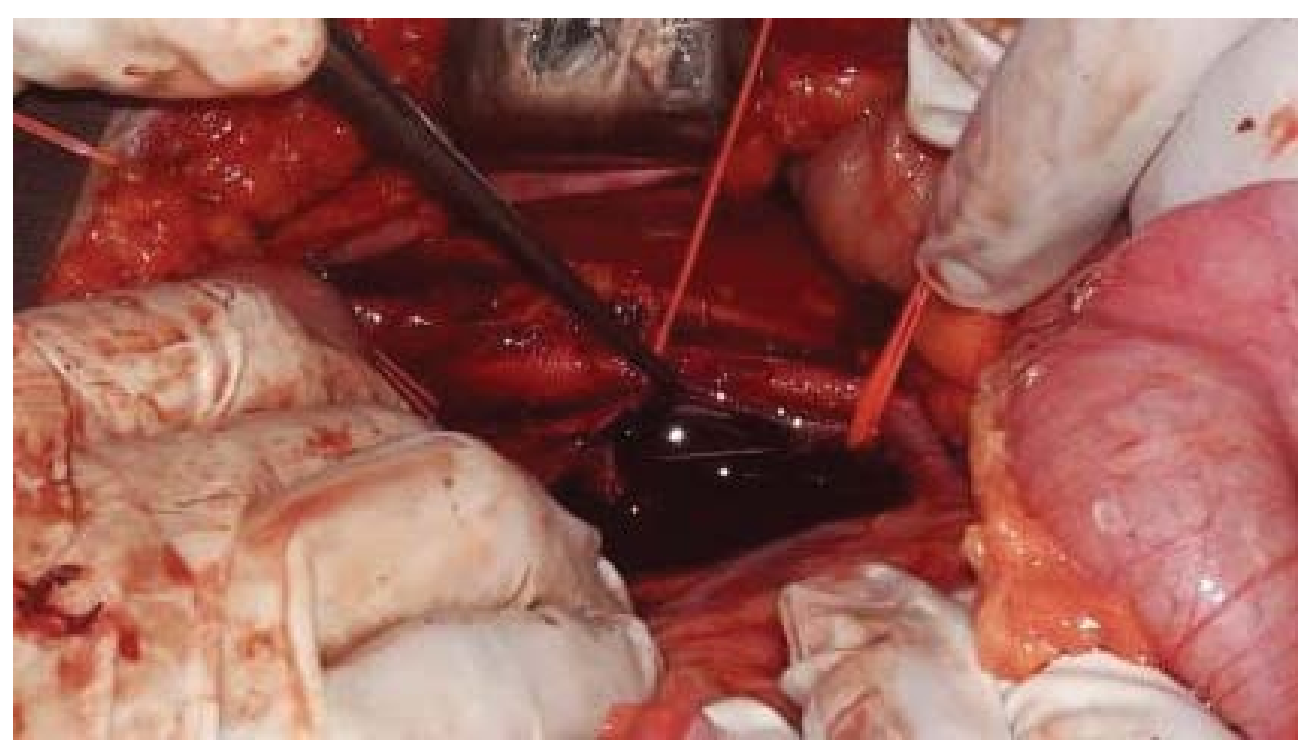

Figure 1: Lateral vena cava injury of approximately $3 \mathrm{~cm}$.

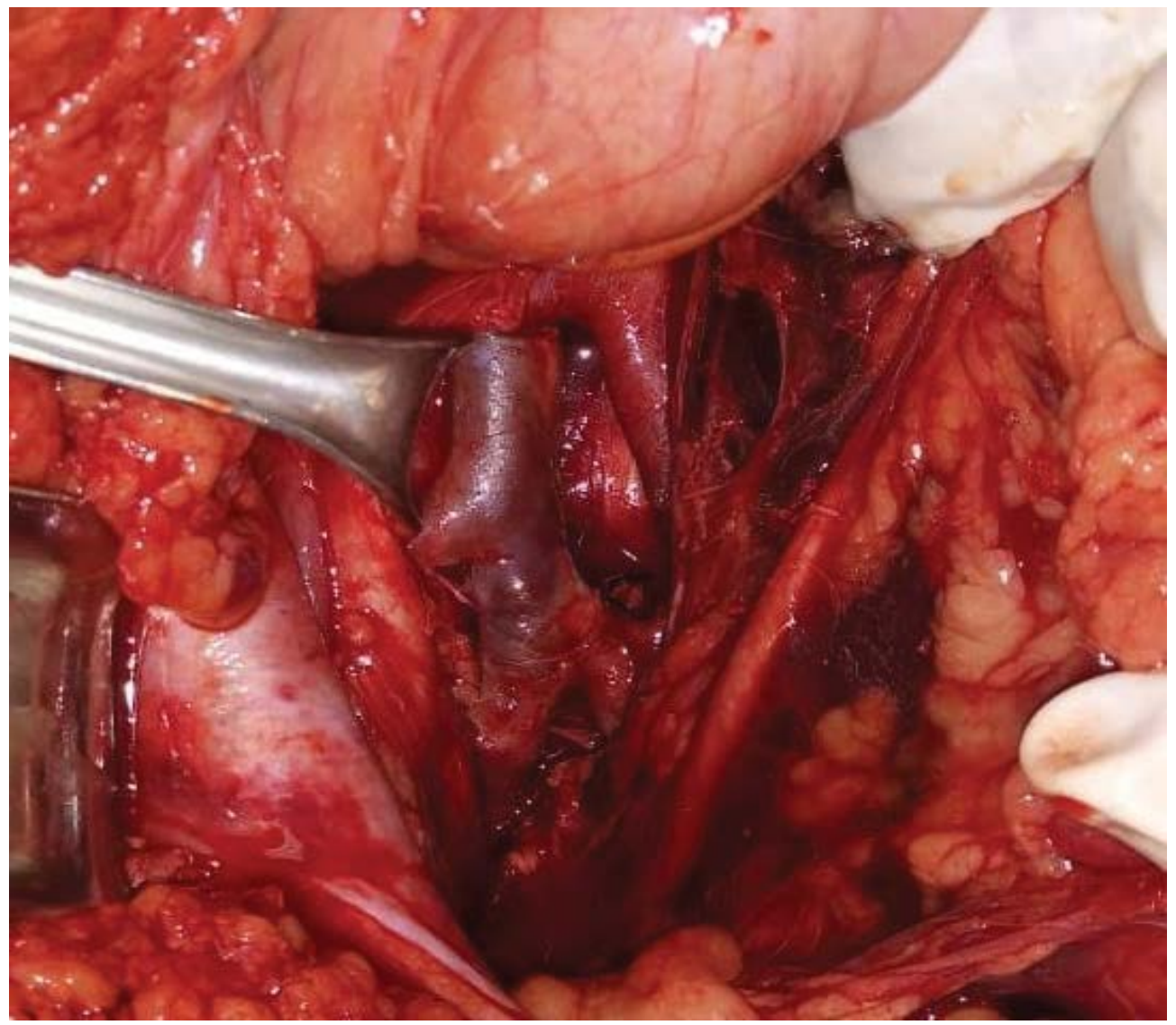

Figure 2: Inferior vena cava reconstruction with continuous 6-0 prolene suture.

On his second post-operative day a Facial tomography was requested, finding fracture of the lower jaw. The patient evolved favorably, we start oral nutrition and removed the open drainage on the third day, also recanalized and evacuation present at fourth day. The surgical repair of the jaw fracture was performed at $6^{\text {th }}$ postoperative day; he was discharged after 8 days of hospitalization.

\section{Conclusion}

Abdominal vascular injuries are associated with a high mortality/morbidity rate representing a challenge for vascular and emergency surgeons. Proper and prompt management requires early diagnosis; surgical intervention in hands of an experienced surgeon with advance knowledge of the retroperitoneal anatomy and of the surgical approaches to access these vessels is crucial. The immediate dissection and reconstruction of damages vessels prevents rapid loss of blood. Despite the complex approach and anatomy of the great retroperitoneal vessels, in the hands of an expert surgeon, survival is possible. 


\section{References}

1. Shah AA, Rehman A, Shah SJ, Haider AH, Zogg CK, et al. (2015) Abdominal gunshot wounds-a comparative assessment of severity measures. J Surg Res 198: 334339.

2. Roberts DJ, Bobrovitz N, Zygun DA, Ball CG, Kirkpatrick $A W$, et al. (2015) Indications for use of thoracic, abdominal, pelvic, and vascular damage control interventions in trauma patients: A content analysis and expert appropriateness rating study. J Trauma Acute Care Surg 79: 568-579.

3. Droz NM, Bini JK, Jafree KA, Matsuura JH (2017) Staged reconstruction of the inferior vena cava after gunshot injury. J Vasc Surg Cases Innov Tech 3: 136-138.

4. Sánchez JM, Menéndez P, Asensio JA (2012) Lesiones vasculares abdominales. Cir Esp 90: 215-221. 